\title{
Rotary dryer for thermo sensitive products
}

\begin{abstract}
To achieve the desired drying objectives in thermal sensitive products, such as medicinal plants, the process chosen should happen under minimally controlled conditions, such as, uniformity of temperature and air velocity, minimizing heat loss and with energy viability and efficiency. If possible, the process must occur using equipment with industrial implementation where the evaporation rate can be controlled. The intermittent drying process, which consist of cycles of exposure of the material to heated air (period of effective drying) and tempering (period of no exposure to heated air), is a great option to preserve the product's quality during the drying process. We propose a new configuration of rotary dryer intended for intermittent drying; observing the configurations of widely applied rotary dryers, the relationship between angular velocity, period and frequency of rotation and laboratory experiments of manufacturing process in intermittent drying. The proposed dryer is efficient for the application of intermittent drying in products with high thermal sensitivity, such as medicinal plants. Making possible uniformity of temperature and air velocity distribution, minimizing heat loss and with energy viability and efficiency, guarantying the product quality.
\end{abstract}

Keywords: intermittent drying, medicinal plants, dryer structures, quality control, drying optimization
Volume 4 Issue 6 - 2020

\author{
Diego A Gonzaga, Mariane BR de Ávila, \\ Naiara C Zotti-Sperotto, Evandro de C Melo \\ Department of Agricultural and Environmental Engineering, \\ Federal University of Viçosa, Brazil
}

Correspondence: Evandro de C. Melo, Full Professor, Department of Agricultural and Environmental Engineering, Federal University of Viçosa, University Campus, 36570-900, Viçosa, MG, Brazil, Email evando@ufv.br

Received: November 04, 2020 | Published: December 08, 2020

\section{Introduction}

Drying is a fundamental process for the conservation of biological products with high water content, such as medicinal plants. This process favors the maintenance and integrity of the chemical constituents responsible for the therapeutic effect of these plants. ${ }^{1}$ The conservation is possible because the drying process reduces the water content to values less than $10 \%$ (wet base), and inhibit the microorganism's growth and the enzymatic reactions, guarantying safety, stability, long expiration date. ${ }^{1,2}$ Moreover, it reduces the initial volume, facilitating transportation with cost reduction and creates conditions for a safe and extended storage.

To achieve the desired drying objectives in thermal sensitive products, such as medicinal plants, the process chosen should happen under minimally controlled conditions, such as, uniformity of temperature and air velocity, minimizing heat loss and with energy viability and efficiency. ${ }^{3,4}$ If possible, the process must occur using equipment with industrial implementation where the evaporation rate can be controlled. The intermittent drying process, which consist of cycles of exposure of the material to heated air (period of effective drying) and tempering (period of no exposure to heated air), is a great option to preserve the product's quality during drying process..$^{5-7}$ The preservation is possible because the tempering period allows the water to translocate from the material interior to the surface, so, during exposure to hot air, the water evaporates without overheating the product. ${ }^{8-10}$ This is, while exposed to heated air, its sensitive heat becomes latent heat to evaporate water in the material surface, keeping a good water evaporation rate.

This type of drying can be achieved in several ways, the most common being, in convective drying, the control of the thermal energy supply either by interrupting the air flow or by changing the temperature of the drying air. However, in both there is the inconvenience that the thermal inertia of the system makes the operation difficult, being necessary to wait for the temperature and air flow to stabilize again when restarting the dryer. In addition, in cases where the time of the intermittent cycles is less than the thermal inertia of the system, it is necessary to remove the product from the dryer and leave it running so as not to deregulate the temperature. This requires greater operational work, in addition to causing damage to the product due to the mechanical stress to which it is subjected. Thus, there is a need to automate the process in order to reduce these problems.

One option to automate this type of intermittent drying, ensuring physical and chemical quality of the product and the constancy of energy supplied, is the use of rotary dryers adapted for thermo sensitive products, such as medicinal plants. Thus, we propose a new configuration of convective rotary dryer intended for intermittent drying; observing the configurations of widely applied rotary dryers, the relationship between angular velocity, period and frequency of rotation and laboratory experiments of manufacturing process in intermittent drying.

\section{Material and methods}

The studies for the dryer development were carried out based on research group experience. The group develop research in a laboratory at the Federal University of Viçosa (UFV), Brazil, with a multidisciplinary research group of medicinal plants that has been conducting studies in this area since 1998.

The lines of research that are currently being studied are: Influence of the drying process on the quality and quantity of the essential oil of medicinal plants. Such as: influence of the storage on the quality and quantity of the essential oil of medicinal plants; use of pre-treatment in the drying process of medicinal plants, for example, ultrasound in liquid environment; development and automation of dryers for medicinal plants; intermittent drying as alternative to the conventional process.

Based on a prototype dryer, which simulates the conditions of a commercial dryer the results of the research and studies are presented below. 


\section{Results}

The analysis of the intermittent drying procedure, applied to the dynamics of a rotary dryer, showed that the correct configuration of the relationship between the frequency of rotation and the angle of application of hot air is equivalent to the dynamics of application and interruption of energy in drying performed in a conventional dryer. Thus, this dryer configuration reduces the operator's need to work to only two interventions (Start and end of drying) and allows you to configure any intermittent ratio by establishing the angular speed, or rotation frequency and the angle of hot air application. The dryer constituents are presented below:

\section{Trays and rotor}

The trays have the function of handling the material that will be dry safely. It has perforated sides or fabrics for cross-passage of drying air (Figure 1A). The rotor is the mobile part of the dryer. It performs rotational movement around the central axis of the cylinder that forms it. It has the function of behaving the trays and distributing the heated air between them according to the speed of rotation to which it is subjected. It has radially positioned and hollowed niches for the trays fitting. It also has the leaked center for the allocation of the plenum of the dryer (Figure 1B).

A

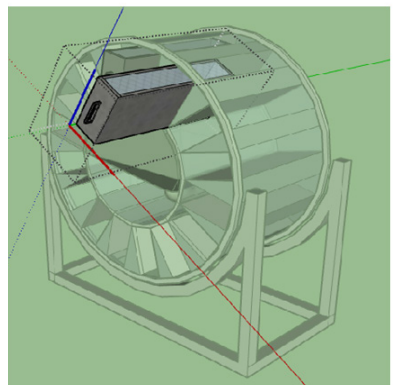

Figure I Trays showed in detail and in the dryer $(A)$; detail of the rotor (B).
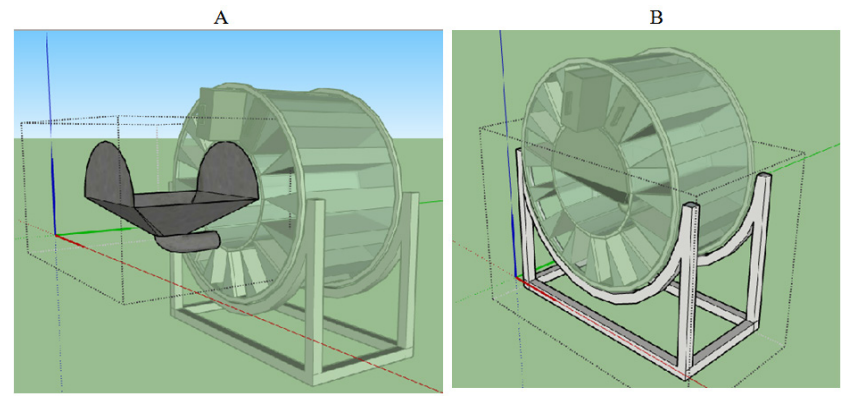

Figure 2 Plenum for air distribution (A); structure that support the dryer (B).

\section{Plenum and base structure}

The plenum has the function of connecting the hot air source to the rotor, homogenizing the airflow and delimiting the angle of drying air application to the rotor with the trays (Figure 2A). The base structure has the function of sustaining the entire structure and providing rotation to the rotor stably (Figure 2B).

The dryer operation rotates the trays. The trays form the top receive the heated air (consisting of the effective drying of the intermittent cycle). While that occurs the trays from the bottom are in tempering period (consisted of no exposure to heated air of the intermittent cycle). This cycle is defined according to the rotation speed and the angle established by the plenum (Figure 3 ).

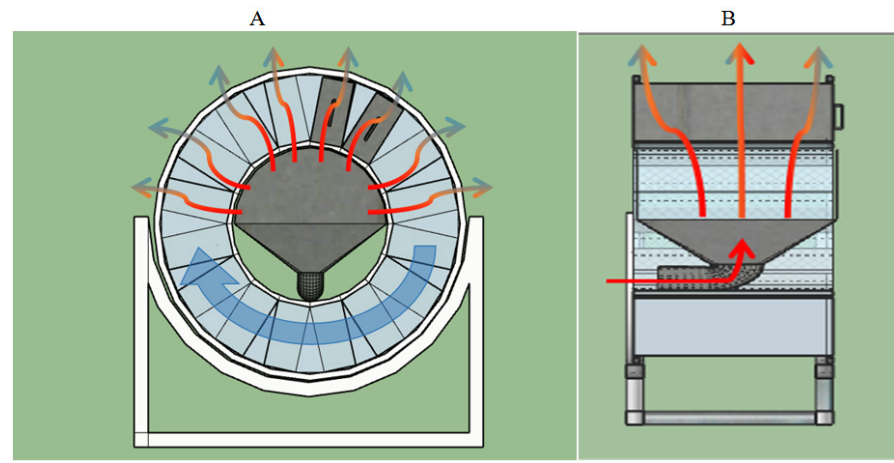

Figure 3 Frontal view of dryer operation with trays from the top receiving heated air while trays from bottom are in period of tempering $(A)$; lateral view from dryer operation (B).

The air distribution arc, formed by the walls of the plenum, determines the established intermittent cycle. Therefore, the plenum must be configured according to the desired intermittent cycle. This configuration can have a fixed construction or be built in such a way as to adjust the air distribution angle according to the operation need (Figure 4).

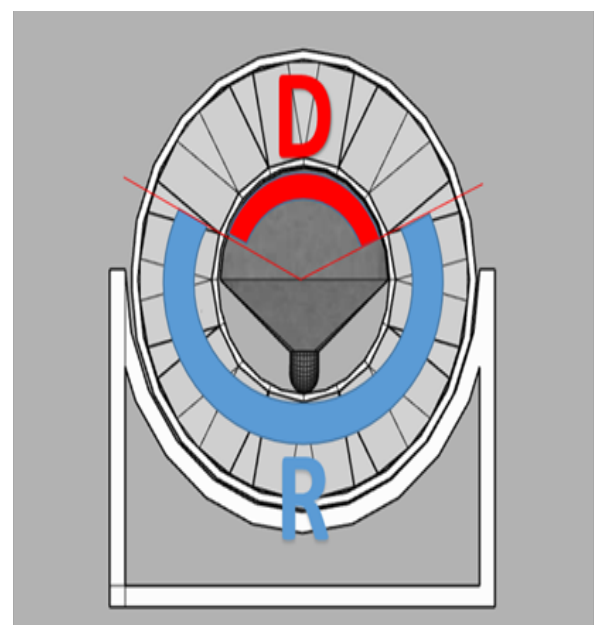

Figure $4 \mathrm{View}$ of angle configuration.

The rotation speed of the rotor determines the exposure and tempering time established on the intermittent cycle. The calculation of angle $\mathrm{D}$ is given by the intermittent cycle and can be calculated by:

$\mathrm{D}=\left(\mathrm{I}_{\mathrm{DT}} / \mathrm{T}_{\mathrm{R}}\right) \times 360^{\circ}$ and $\mathrm{R}=$ Difference between $\mathrm{D}$ and $360^{\circ}$ $\left(360^{\circ}-\mathrm{D}\right)$.

Where: air)

$I_{D T}=$ the effective drying time (when product is exposed to heated

$\mathrm{T}_{\mathrm{R}}=$ the total time of each intermittent cycle (effective drying time + tempering time).

This proposal of constructive configuration for intermittent drying rotary dryer brings a new perspective of modeling and process development in the production chain of thermo sensitive agricultural products that require intermittent drying processes.

The proposed dryer is specifically designed for the application of intermittent convective drying processes since its structural configuration determines the relationships between the drying and resting cycle. 
It solves issues such as the inconvenience of the system's thermal inertia hindering the operation, being necessary to wait for the temperature and air flow to stabilize, in case of interruption of the energy supply, and mechanical stress to which it is submitted and operational work in the drying, in the case of the need to remove the product from the dryer at each intermittent cycle.

With this device, energy is effectively used because, when rotating the trays, drying air is applied intermittently with each revolution of the rotor while the energy supplied to the equipment remains stable.
Its application avoids overheating the surface of the product, inhibiting the formation of dry crusts and facilitates subsequent drying on the inner parts of the product. This ensures that no damage occurs due to overheating, such as volatilization of important compounds, and even less, loss of dry mass due to carbonization, allowing uniformity in the distribution of temperature and air speed, minimizing heat losses and with viability and energy efficiency, ensuring product quality (Table 1).

Table I Table comparing advantages and disadvantages between tray dryers, rotary dryers and the proposed Rotary dryer for intermittence

\begin{tabular}{|c|c|c|}
\hline Dryers /drying technologies & Benefits & Disadvantage \\
\hline \multirow[t]{6}{*}{ With Trays. ${ }^{8,11}$} & $\begin{array}{l}\text { - It allows the programming of several drying } \\
\text { parameters, }\end{array}$ & - Difficulty in uniform distribution of air flow. \\
\hline & $\begin{array}{l}\text { - Enables adaptation of the process to different } \\
\text { parts of the plant. }\end{array}$ & $\begin{array}{l}\text { - Difficulty in uniformity of the water content of the } \\
\text { final product. }\end{array}$ \\
\hline & - Can operate in combination with other dryers. & - It can cause the product surface to overheat. \\
\hline & - Enables large-scale operation. & \\
\hline & - Results in good retention of compounds of intere & \\
\hline & - Low implementation cost. & \\
\hline \multirow[t]{2}{*}{ Rotary Dryer 8 ,11 } & $\begin{array}{l}\text { - Allows you to use different types of heat } \\
\text { transfer. }\end{array}$ & $\begin{array}{l}\text { - Difficulty in uniformity of the water content of the } \\
\text { final product. }\end{array}$ \\
\hline & - Can be adapted to dry various types of product. & $\begin{array}{l}\text { - Difficult mathematical modeling due to large } \\
\text { variations in equipment. }\end{array}$ \\
\hline \multirow[t]{8}{*}{ Rotary dryer for intermittence } & $\begin{array}{l}\text { - Enables adaptation of the process to different } \\
\text { parts of the plant. }\end{array}$ & - Higher construction cost. \\
\hline & - Can operate in combination with other dryers. & - Less volumetric use of the dryer. \\
\hline & - Enables large-scale operation. & \\
\hline & \multicolumn{2}{|l|}{ - Results in good retention of compounds of interest. } \\
\hline & \multicolumn{2}{|l|}{ - Can be adapted to dry various types of product. } \\
\hline & \multicolumn{2}{|l|}{ - Product compartmentalization. } \\
\hline & \multicolumn{2}{|l|}{ - Low mechanical stress to the product. } \\
\hline & \multicolumn{2}{|c|}{ - Intermediate drying without interruption of the process energy source. } \\
\hline
\end{tabular}

\section{Conclusion}

The dryer proposed is efficient for application intermittent drying in thermo sensitive products, such as medicinal plants. Making possible uniformity of temperature and air velocity distribution, minimizing heat loss and with energy viability and efficiency, guarantying the product quality.

\section{Acknowledgments}

This work was supported by the coordenação de aperfeiçoamento de pessoal de nível superior (CAPES) [Fiance code 001].

\section{Conflicts of interest}

Authors declare no conflict of interest exists.

\section{References}

1. Müller J, Heindl A. Drying of medicinal plants. In: editors. Bogers RJ, Craker LE, et al. Medicinal and Aromatic Plants. Springer: Netherlands, 2006;237-252.
2. Chan JWR, Chong $\mathrm{CH}$, Abdul Malek NF, et al. Trends in drying and extracting bioactive components from herbs. In: editors. Hii CL \& Jangam SV, et al. Processing of Foods, Vegetables and Fruits: Recent advances. Singapore, 2015;85-104.

3. Kudra T, Mujumdar AS. Advanced drying technologies. 2nd ed. CRC Press: New York, 2009.

4. Martynenko A, Kudra T. Non-isothermal drying of medicinal plants. Dry Technol. 2015;3937:150202232226005.

5. Chou SK, Chua KJ, Mujumdar AS, et al. On the intermittent drying of an agricultural product. Inst Chem Eng. 2000;78:193-203.

6. Chin SK, Law CL. Product quality and drying characteristics of intermittent heat pump drying of ganoderma tsugae murrill. Dry Technol. 2010;28:1457-1465.

7. Jin W, Mujumdar AS, Zhang M, et al. Novel drying techniques for spices and herbs: a review. Food Eng Rev. 2018;10:34-45.

8. Mujumdar AS, Law CL. Drying technology: trends and applications in postharvest processing. Food Bioprocess Technol. 2010; 3:843-852. 
9. Kumar C, Karim MA, Joardder MUH. Intermittent drying of food products: A critical review. J Food Eng. 2014;121:48-57.

10. Barbosa de Lima AG, Delgado JMPQ, et al. Intermittent drying fundamentals, modeling and applications. In: Delgado JMPQ, Barbosa de Lima A, editors. Drying and energy technologies. Springer International Publishing: Switzerland, 2015;1-228.
11. Mujumdar AS. Handbook of industrial drying, Third. CRC Press: Boca Raton, FL, 2007. 